\title{
Feasibility of a Cost-effectiveness Analysis Examining Interventions for Abused Persons with Mental Disabilities
}

\section{Abstract}

Background: Japan implemented new legislation to prevent the abuse of persons with disabilities on Oct 1, 2012. Many specialists from various domains participated in the development of interventions to prevent such abuse. Here, we conducted a pilot analysis to examine the cost of such interventions and to explore differences in caseloads. In particular, we compared caseloads for the assistance of victims with mental disabilities with those for the assistance of victims with other disabilities.

Methods and Findings: We requested the enrollment of the anonymous case records of 16 local governments. Thirteen municipal/certified centers reported 41 cases, including 42 victims. Of them, 12 victims had mental disabilities. We calculated both the time and human/social resources consumed per case until the resolution of the case. The median length of time from the start of the intervention until the solution of the claimed crisis was 162 days for the cases with mental disabilities, compared with 129 days for the other cases. However, an analysis of 22 familial cases did not reveal a significant relation between the type of disability and the caseload.

Conclusions: Although the existence of mental disabilities did not seem to impact the caseload, our method of analysis worked well. The accumulation of more cases is warranted.

Received: November 13, 2015; Accepted: December 04, 2015; Published: December 08,2015

\section{Introduction}

In Japan, the Regional Legal Affairs Bureau has consulted on cases of the violation of basic human rights of persons with disabilities. In addition, municipal social welfare offices have supplied advocacy systems for such persons. Nevertheless, specialized legislation applicable to abused individuals with disabilities is required.

Prior to the ratification of the Convention on the Rights of Persons with Disabilities, Japan enacted a nationwide law for the prevention of the abuse of persons with disabilities in October 1, 2012. The new law "Law Pertaining to Abuse Prevention of Persons with Disabilities and Supports of Their Guardians" (Abuse Prevention Act for Persons with Disabilities) (Act No. 79 of 2013) defines five types of abuse that may be inflicted by any of three types of offenders ( 15 forms in total) and targets victims between the ages of 18 and 64 years, providing a due process protection

\section{Toshihiro Horiguchi' Kenji Takanashi ${ }^{2}$, Shoichi Sato ${ }^{3}$, Toshikazu Shiga ${ }^{4}$}

1 National Institute of Mental Health Department of Social Psychiatry (Japan)

2 Social Welfare Corporation AIKOH Headquarters (Japan)

3 KOKUGAKUIN University Law School (Japan)

4 The National Center for the Persons with Severe Intellectual Disabilitites, NOSOMINOSONO Division of Research (Japan)

\section{Corresponding author:}

Toshihiro Horiguchi

Department of Social Psychiatry, National Institute of Mental Health, National Center of Neurology and Psychiatry, 4-1-1 OgawaHigashi, Kodaira City, Tokyo 187-8553, Japan.

\section{horigti@ncnp.go.jp}

Tel: +81-423-41-2711

Fax: +81-426-1989 program for victims (Table 1 and Figure 1). All local governments (including 1,742 cities and 47 prefectures) were required to establish centers for prevention and advocacy. Anyone witnessing an abuse is obligated to notify the centers. In addition, health specialists are encouraged to pursue early detection (Table 1 and Figure 1). The Ministry of Health, Labour and Welfare (MHLW) annually collects data on the total number of services provided by each center. Their periodical report [1] counted 1,311 cases registered by family member, 80 cases registered by institution specialists, and 133 cases registered by employers during the first 6 months after the implementation of the law. Of them, $36.0 \%$ of the 1,329 victims reported by families, $39.3 \%$ of the 176 victims reported by institution specialists, and 3 (1.5\%) of the 194 victims reported by employers had mental disabilities. As part of basic data collected in Japan, governmental surveys [2] have shown that 3.77 million of 3.83 million (98.4\%) persons (18 years and older) with physical disabilities, 0.47 million of 0.58 million 
Table 1 Definitions of abuse in the new legislation.

\begin{tabular}{|c|c|}
\hline Type of abuse Ex & Explanation \\
\hline Physical & $\begin{array}{l}\text { 3odily injury or such potential assault Arbitrary } \\
\text { estriction }\end{array}$ \\
\hline Sexual & $\begin{array}{l}\text { exual assault, forced to perform sexual } \\
\text { ehaviors }\end{array}$ \\
\hline Psychological & $\begin{array}{l}\text { lerbal aggressiveness, negative or } \\
\text { discriminative response leading to psychological } \\
\text { rauma }\end{array}$ \\
\hline Neglect & ndifference or inattention to care required \\
\hline Financial & $\begin{array}{l}\text { Unfair disposal of properties } \\
\text { Exploitation of profits } \\
\text { e.g., social securities) }\end{array}$ \\
\hline $\begin{array}{l}\text { Perpetrator (setting } \\
\text { of abuse) }\end{array}$ & Ig Explanation \\
\hline Family member(s) & $\begin{array}{l}\text { Person(s) substantially incharge of care, with the } \\
\text { exception of individuals } \\
\text { described below } \\
\text { (Including relatives and } \\
\text { family-in-laws) }\end{array}$ \\
\hline $\begin{array}{l}\text { Institutional } \\
\text { professional }\end{array}$ & $\begin{array}{l}\text { Employees of both residential } \\
\text { and outpatient facilities for } \\
\text { persons with disabilities }\end{array}$ \\
\hline Employer & $\begin{array}{l}\text { Entrepreneur or contractor } \\
\text { (Including contractors provided } \\
\text { by temp agencies) }\end{array}$ \\
\hline
\end{tabular}

(81.0\%) persons with intellectual disabilities, and 2.69 million of 3.01 million (89.4\%) persons with mental disabilities (i.e., persons with psychiatric disorders who have been issued a disability identity card) live in the community. Another report [3] indicated that $76.8 \%$ of outpatients with mental disabilities live with their own families, though only 29,000 persons were employed at companies (business institutions with more than five employees). Since many unemployed people with mental disabilities live with their families, this may increase the risk of abuse from the family. Furthermore, the number of victims with mental disabilities was the second largest, followed by the number of victims with intellectual disabilities, to be reported by family and institutional cases. Thus, the presence of a mental disability might increase the risk of abuse [4].

An assessment of interventions is needed to check the due process given for each type of abuse. In the MHLW report [1], although the totaled cross-sectional data summarized the activities of centers nationwide, the contents of interventions for individual cases were not available. To analyze the contents of intervention, we designed a study measuring caseloads according to time and cost required per case. Apart from international differences in social security systems, such comprehensive works seem to be sparse worldwide despite the magnitude of this issue. Therefore, our trial will be the first report regarding the abuse of persons with disabilities in Japan. We hypothesized that interventions for

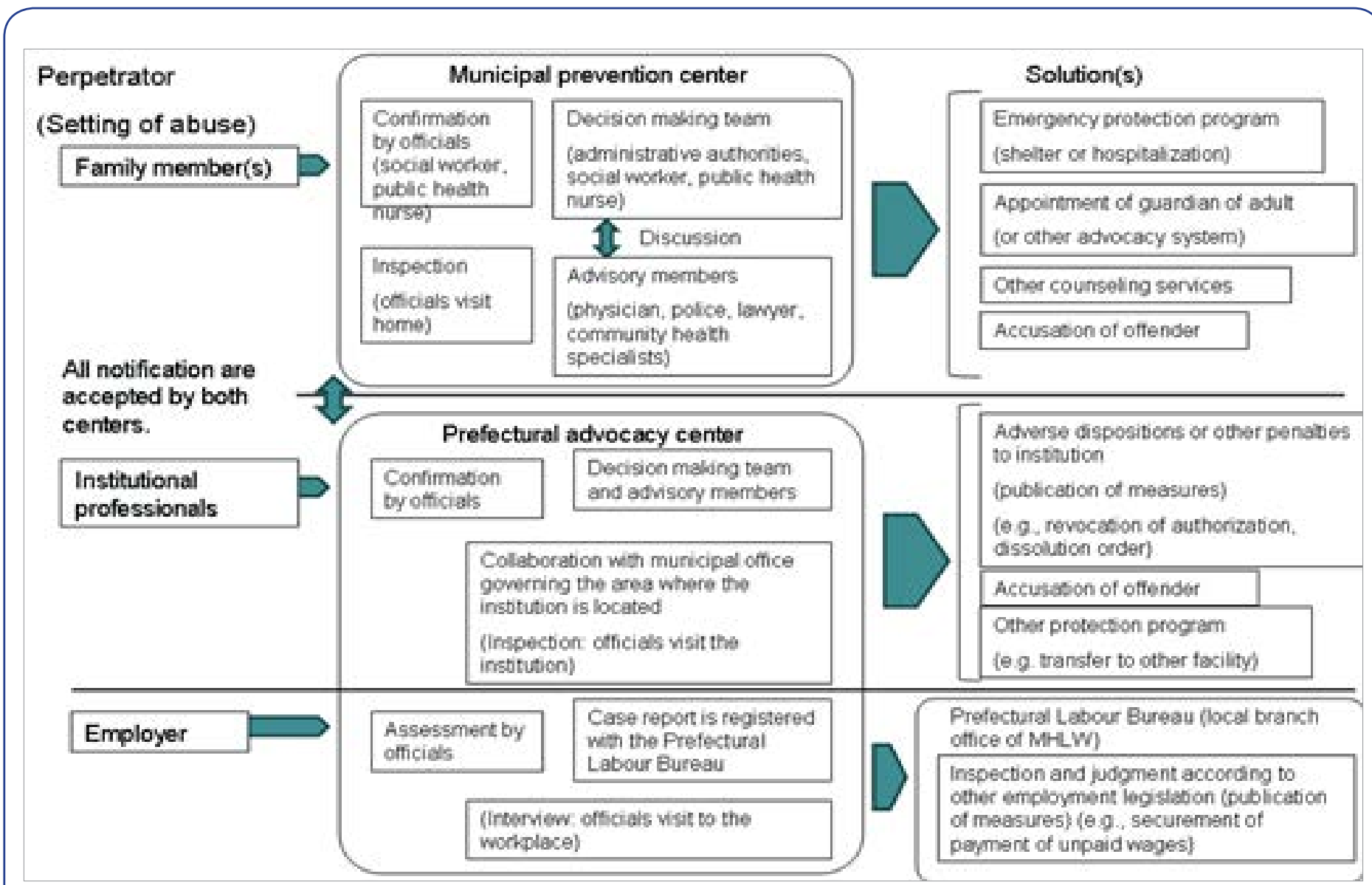

Scheme showing legislative interventions for each type of abuse. 
mental disabilities might require a longer time and/or a higher expense, compared with those for other disabilities.

\section{Methods}

We held preliminary hearings with social welfare officials from 17 local governments to obtain opinions regarding measures of abuse. One city declined to participate, so we requested the anonymous case records from 16 local governments (13 cities and 3 prefectures) that had been recognized as being advanced in regards to this issue prior to the enactment of the law.

In addition, since we wished to review completed cases despite our study occurring within the first year of the enactment of the new law, we requested case reports from private counseling centers authorized by Chiba Prefecture. These centers had experienced many cases of abuse as part of an advocacy program created by the Chiba Prefecture Ordinance for the Solution of Discrimination to Persons with Disabilities, which was enacted in 2007 (Act No. 52 of 2007; last amendment Act No. 22 of 2012). After the enactment of the Abuse Prevention Act for Persons with Disabilities, some of these centers were entrusted by the cities where they were located.

We created case records containing information pertinent to our study. The profile for each case included the type(s) of abuse and the offender(s), the onset, frequency, severity, and content of the abusive behaviors, and the characteristics of the victim (gender, age, disabilities).

In addition, we collected details of the interventions performed for each case, including time (date, time required, and duration), experts engaged (number of persons; and their specialties and positions), and the contents of the interventions, describing the interventions in a manner similar to that of a medical record.

We required that the cases included in this study satisfy all of the following conditions: a positive judgment (recognition of abuse having occurred), and the commencement and completion of an intervention after the enactment of the law. If no such perfect cases were available, we allowed the expert in charge of the case to relax the criteria.

To complete each record, experts removed all personal information and recalled the contents of the intervention as completely as possible. They provided a number for each case record in the event that further inquiry was needed. Only the experts in charge of the cases were aware of how the case numbers corresponded to the actual cases.

\section{Case recruitment started in October 2013.}

We calculated both the time and human/social resources consumed per case until the resolution of the case. For every intervention, the involvement of professionals was converted into their estimated wages for on-duty hours. (Figure 2) Each case record was calculated separately, since the salaries of officials vary according to region and the salaries of employees differ individually, although we adopted identical values for each type of professional to balance the results. Such medico-economical measurements were validated in our previous study [5] (Figure 2).
In the present report, the total time and cost required until a solution was reached were compared according to the type of disability, since the setting of the abuse (type of offenders) decides the due process.

A multiple regression analysis using dummy variables was performed for the statistical analysis.

This research was approved by the ethical examination board of the National Center of Neurology and Psychiatry (ID: A2013073). The study protocol met the national ethical guidelines for epidemiological studies.

We converted the work of every person appearing in the case records into an hourly rate equivalent. The wages in the table 2 were drawn from various official publications. Hourly wages were calculated according to the national average monthly salary for every specialist. We ignored differences in age when calculating the average salary of specialties. We calculated an overtime wage of 1.5 times the normal hourly wage for duties performed at times outside of 8:30-17:15 on weekdays or for duties performed on national holidays (Table 2 ).

In completing the case records for our study, the specialty of each person involved was required. If the specialty of a person was identified, his/her wage was determined based on that specialty.

\section{Results}

As of March 2014, 13 municipal/certified centers reported 41 cases, including 42 victims. Six cases were experienced before the enactment of the law.

- Twenty-two victims were females and 20 were males.

- Thirteen victims (31.0\%) were in their $40 \mathrm{~s}$.

- The perpetrators were mainly family members or relatives in 22 cases $(52.4 \%)$, institution professionals in 9 cases, and employers in 10 cases. Among the familial offenders, 8 of the perpetrators had mental disabilities and 1 was suspected of having a mental disability.

- The type of abuse was complex abuse in 18 cases and singletype abuse in 22 cases.

- Four cases were ultimately judged as not being abuse. Overall, physical abuse was reported in 24 cases, sexual abuse was reported in 4 cases, psychological abuse was reported in 17 cases, neglect was reported in 7 cases, and financial abuse was reported in 10 cases. The severity of the abuse was rated as mild in 8 cases, moderate in 6 cases, severe in 4 cases, and profound in 7 cases.

- Six victims (14.3\%) had 2 or more disabilities, and 12 had mental disabilities. Of these victims, the co-occurrence of different types of abuses occurred in 6 cases (50.0\%); 8 cases (66.7\%) were abused physically, and 6 cases (50.0\%) were abused psychologically.

- As a solution, a guardian was appointed in 5 cases. Separation or institutional hospitalization was performed for 6 cases. The perpetrators had died in 2 cases; among the registered cases, none of the victims had died. 
【Case A】

Date

$\mathrm{mm} / \mathrm{dd}$

$\mathrm{mm} / \mathrm{dd}$

$\mathrm{mm} / \mathrm{dd}$

$\mathrm{mm} / \mathrm{dd}$

Notification Case

Perpors's) Case

worker $A$

Work Telephore $(n)$

Time and Hour(t) $y$

(h) (from hamm to

homin)

Detailed data that

was as precise as

possible was

requested.

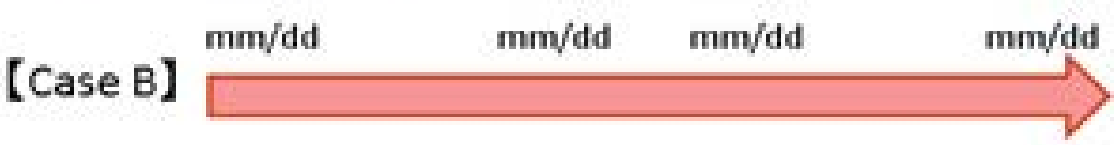

Personc CWA FNo $e$ for

B. Polioman $C(x)$ judgment

Meuns Automobie Person Dedion

Time and Heurb) $Y$ Making Team ( 2 )

(from ihsen to to time and

Hour(s): y

gtrom hesim to

hemey

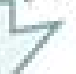

\section{Inspection Conferenc}

Solution

Means:

Time and Hour(s): $y$

\section{Consumption for Case A}

[Dass] $x_{\text {, days }}$

(duration from acceptance of notification until solution)

[Time] $\mathbf{y}, \mathbf{h}$

(actual accumulated working hours)

[Persons] 2 .

(accumulated number of specialists directly engaged]

[tabor cost] $x_{5}{ }^{*} y$, yen

(accumulated labor costs by all persons)

\section{Consumption for Case B \\ [Days] $x_{0}$ days \\ [Time] y, hrs. \\ [Persons] $z_{6}$ \\ [Labor cost] $x_{b}{ }^{*} y_{b}$ yen}

Totaled across cases

Figure 2

Caseload analysis (example).

Table 2 Table for labor costs.

\begin{tabular}{|c|c|c|}
\hline Professionals & $\begin{array}{c}\text { Hourly } \\
\text { wages (JPY) }\end{array}$ & Included in this study \\
\hline Psychiatrist (working at Mental Hospital) & 7,498 & Other physicians \\
\hline Nurse (working at Mental Hospital) & 2,346 & Nurse working at other outpatient facilities \\
\hline Certified PSW (working at Mental Hospital) & 1,887 & Other medical social worker \\
\hline Occupational Therapist (working at Mental Hospital) & 2,144 & Physical therapist \\
\hline Other workers (working at Mental Hospital) & 1,615 & Psychologist \\
\hline Lawyer (counseling fee per hour) & 5,000 & Lawyer as advisory member \\
\hline Nurse, Public Health Nurse (Municipal officer at major city) & 2,604 & PHN as a prefectural administrative official \\
\hline Social worker (working at private welfare facility) & 1,034 & Worker at private advocacy center \\
\hline Social worker or other care worker (working at private institution) & 1,426 & \\
\hline $\begin{array}{l}\text { Social worker or other care worker (working at prefectural } \\
\text { institution) }\end{array}$ & 2,504 & \\
\hline Municipal officials in administrative service & 2,924 & \\
\hline Prefectural officials in administrative service & 2,794 & \\
\hline Policeman (prefectural officer) & 2,986 & \\
\hline National officials in administrative service & 2,352 & $\begin{array}{l}\text { Officials of The Public Employment Security Office, Prefectural } \\
\text { Labour Bureau }\end{array}$ \\
\hline Associate professor at a university & 3,275 & Advisory member as a person of learning and experience \\
\hline $\begin{array}{l}\text { Home helper (home care worker for elderly or persons with } \\
\text { handicaps) }\end{array}$ & 1,364 & \\
\hline Care manager (nursing care manager) & 1,618 & \\
\hline High school teacher (prefectural officer) & 2,819 & High school teacher for special needs education \\
\hline
\end{tabular}

- The total number of interventions among all the records was 1,724; of these interventions, 55 were performed during offduty hours.

- Among the victims with mental disabilities, 8 (30.8\%)

were victims of familial abuses, $3(33.3 \%)$ were victims of institutional abuse, and $1(9.1 \%)$ was abused by his or her employer. Eight of the 12 cases (66.7\%) with familial abuse had mental disabilities. 
- The median length of time from the start of intervention until the resolution of the claimed crisis was 162 days for the psychiatric cases and 129 days for the other cases.

- The median values seemed to differ depending on whether the cases had mental disabilities; cases with mental disabilities required longer interventions, as indicated by the number of hours worked by specialists and the higher labor cost (Table 3).

However, data regarding the costs associated with psychiatric cases varied widely (Figure 3).

- Many victims had more than one disability, and the existence of each disability was not exclusive of other disabilities. Therefore, the existence of each disability was regarded as an independent variable, and the total time and cost required until a solution was reached were regarded as dependent variables.

- An analysis of the 22 familial cases did not reveal a significant relation between the type of disability and the caseload (time: $\mathrm{F}=0.66, p=0.63, \mathrm{r}^{2}=0.13$, labor cost: $\mathrm{F}=0.84, p=0.52, \mathrm{r}^{2}$ $=0.16)$. An analysis using two classes of factors simultaneously (disabilities and type of abuse) could not be performed because of the small sample size.

Table 3 Differences in median values according to the presence of a mental disorder.

\begin{tabular}{|c|c|c|c|c|}
\hline \multirow{2}{*}{\multicolumn{2}{|c|}{ Variables }} & \multirow{2}{*}{$\begin{array}{l}\text { Whole sample } \\
\qquad(n=41)\end{array}$} & \multicolumn{2}{|c|}{ Mental disorder } \\
\hline & & & $-(n=29)$ & $+(n=12)$ \\
\hline \multicolumn{2}{|c|}{ (a) Days of intervention (days) } & 15 & 11 & 16 \\
\hline \multicolumn{2}{|c|}{ (b) Total number of days (days) } & 17 & 17 & 16 \\
\hline \multicolumn{2}{|c|}{ (c) Total length of time for intervention (h) } & 15.38 & 9.50 & 18.50 \\
\hline \multicolumn{2}{|c|}{ (d) Total number of specialists working for intervention } & 33 & 32 & 42.5 \\
\hline \multirow{6}{*}{$\begin{array}{l}\text { (e) Total amount of } \\
\text { time spent for each } \\
\text { intervention }(\mathrm{h})\end{array}$} & talking on the telephone & 2.25 & 3.12 & 1 \\
\hline & conference & 4.5 & 3.25 & 9 \\
\hline & decision making conference (other than above) & 2 & 2 & 2 \\
\hline & confirmation of facts & 2.25 & 1.92 & 3.25 \\
\hline & visits for inspection & 3.75 & 3.5 & 5 \\
\hline & accompanying visit to hospitals (both perpetrators and victims) & 4.5 & 4.5 & 4.5 \\
\hline \multicolumn{2}{|c|}{ (f) $c^{*} d$ summed for each case } & 35 & 26 & 58.50 \\
\hline \multicolumn{2}{|c|}{ (g) Total labor cost for each case (JPY) } & $76,330.5$ & 68,464 & 159,558 \\
\hline
\end{tabular}

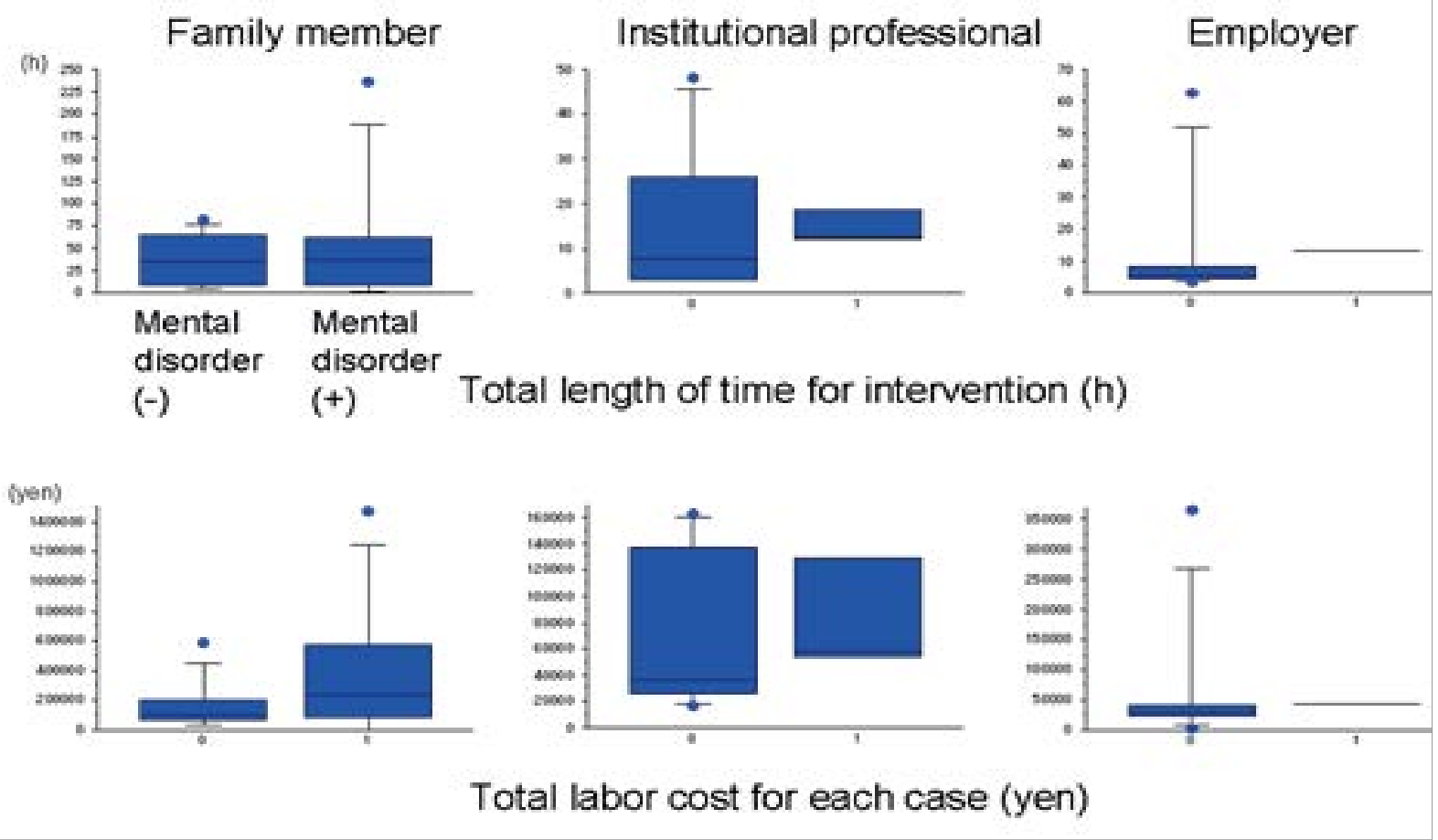

Figure 3 Distribution of data for two variables according to presence of mental disorders. 


\section{Discussion}

Many reports have confirmed that the presence of a disability increases the risk of being abused. Determining the contents of interventions for abused individuals with disabilities will help to standardize the expected caseload for each type of disability, enabling local governments to set budgets sufficient to cover the predicted annual costs.

In many cases, both the perpetrator and the victim had a mental disability. More than a half of the presently reported cases were abused by their families, and many of these perpetrators had a mental disability. The prevalence of mental disabilities resembled the results of a national report. Thus, our sample did not deviate remarkably from the overall results for Japan. Many of the persons with mental disabilities were unemployed and lived with their families; thus, they were often abused. To prevent abuse in families, social resources within the community, such as day care centers, are needed not only to provide free time to both sides, but also to check for maltreatment.

The caseload for the abuse of individuals with mental disabilities did not differ in our sample. Cases with mental disabilities did not require a significantly longer time or cost until a solution was reached, compared with cases with other disabilities. We are convinced that all the experts involved with the interventions for these cases met their responsibilities appropriately. Therefore, our results suggest that local governments can set budgets based on the number of anticipated cases. Of course, all the centers in the present study employed experts who specialized in helping abused individuals with disabilities. The training of additional members is necessary.

Our study had various limitations, such as the relatively small number of cases and a mixture of cases with diverse conditions. However, our analysis method worked well. A model that can effectively predict the caseload based on the case profile could be obtained using a larger sample. Consequently, the accumulation of more cases is warranted.

\section{Funding}

This research was supported by the Health and Labour Sciences Research Grants by the Ministry of Health, Labour and Welfare (H25-physical and intellectual-general-007, Principal Investigator: Toshihiro Horiguchi).

\section{Competing Interests}

No competing interests exist. 


\section{References}

1 Department of Health and Welfare for Persons with Disabilities MHLW (2013) The report on the Abuse Prevention Act for Persons with Disabilities.

2 The Cabinet Office (2014) Annual report on government measures for persons with disabilities.

3 The Cabinet Office (2013) Annual report on government measures for persons with disabilities.
4 Hughes K, Bellis MA, Jones L, Wood S, Bates G, et al. (2012) Prevalence and risk of violence against adults with disabilities: a systematic review and meta-analysis of observational studies. Lancet 379: 1621-1629.

5 Horiguchi T, Tashiro N (2012) [Activity report on a preliminary program for the utilization of school social workers] The Journal of Child Health 69: 823-829. 